\title{
PRESENTACIÓN
}

\section{El discurso \\ y sus discursos en la mira}

\author{
Eva Salgado Andrade
}

$\mathrm{D}$ e manera creciente, la noción de discurso y sus posibilidades analíticas para la investigación social se imponen en diversas ramas de la antropología, la historia, la sociología, la psicología social, la ciencia política o las ciencias de la comunicación. De igual forma, desde los terrenos de la lingüística y la semiótica el estudio del lenguaje en la vida humana adquiere sentido en tanto que se le ubica no como un fenómeno aislado, sino como producto de circunstancias sociales específicas, $c u-$ yo conocimiento no puede dejarse de lado. Así, el hilo conductor de los artículos reunidos en este número es el concepto de "discurso", definido por Gilberto Giménez como "toda práctica enunciativa considerada en función de sus condiciones sociales de producción, que son fundamentalmente condiciones institucionales, ideológico-culturales e histórico-coyunturales" (Giménez, 1981: 124), es decir, el lenguaje puesto en acto y en el cual se materializan las relaciones de poder y de control con base en las cuales funcionan las sociedades.

En el diálogo interdisciplinario que la lingüística y la semiótica han entablado con otras ciencias sociales una tarea que parece urgente es la de contribuir al diseño y aplicación de propuestas teóricometodológicas que articulen los diversos niveles de análisis y permitan, por tanto, vincular los conocimientos en torno al funcionamiento y estructura del lenguaje verbal y no verbal con las circunstancias culturales y sociales de enunciación de las que parten y a cuya construcción contribuyen. A este respecto, es pertinente recordar importantes trabajos teórico-metodológicos que tienen como eje central el concepto de "discurso" y proponen vías para emprender, mediante el mismo, investigación en diversas ciencias sociales, lo cual supone también ampliar la mirada de la investigación lingüística y semiótica. En la lista figurarían, por orden de aparición, la obra pionera de Fowler et al. (1983), que explora la dimensión social del lenguaje y sus vínculos con el poder, hasta otras más centradas en propuestas metodológicas generales, como las de Fairclough (1995), Calsamiglia y Tusón (1999), Renkema (1999), van Dijk (2000a y 2000b), Chilton y Schäffner (2002), Gee (2002), Wodak y Meyer (2003), Bolívar (2007) y Pardo (2007).

\section{Discourse and its Discourses in the Aim}

Eva Salgado Andrade: Centro de Investigaciones y Estudios Superiores en Antropología Social-Distrito Federal, México esalgado@ciesas.edu.mx

Desacatos, núm. 43, septiembre-diciembre 2013, pp. 7-12 


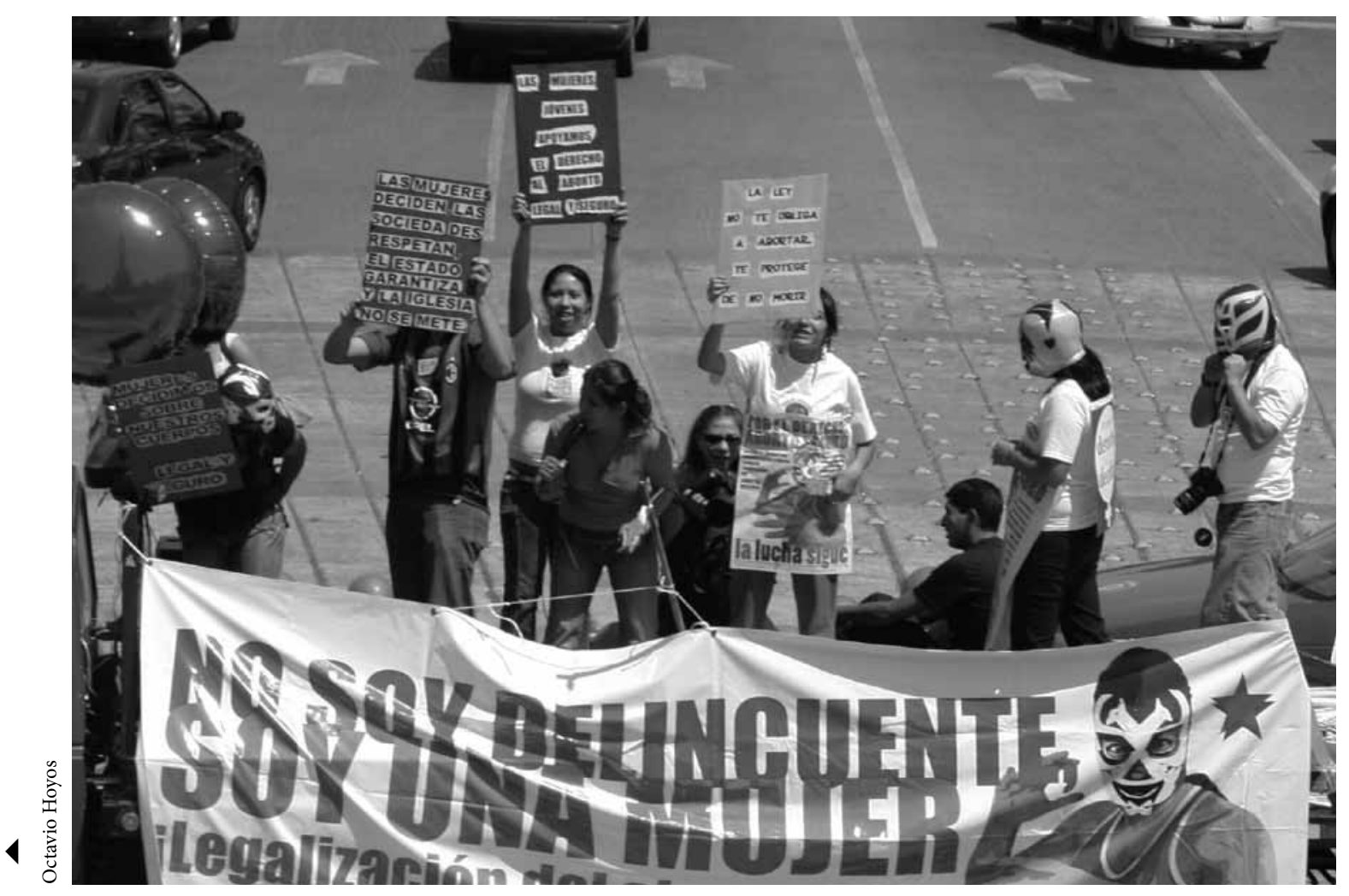

Caravana Proaborto, 2007.

Estas investigaciones tienen dos características en común: establecer algunas condiciones mínimas para concebir el discurso como una evidencia material de fenómenos de indudable interés para las ciencias sociales y plantear estrategias metodológicas para los acercamientos al estudio de la interacción social, el análisis conversacional como una dimensión microsocial, los vínculos entre lenguaje y poder, el lenguaje y su relación con la identidad tanto individual como colectiva, el lenguaje y la vida política, el discurso enmarcado en el terreno de los análisis cualitativos y muchos más. Estos autores, entre otros, han impulsado un diálogo constante entre analistas que practican variantes de estudios del discurso, tanto en México como en otros países. Prueba de ello son los casi 20 años de existencia de la Asociación Latinoamericana de Estudios del Discurso o del seminario de la Red de Estudios del Discurso, ${ }^{1}$ instancias que de manera ininterrumpida han alentado estas reflexiones. Asimismo, en los ámbitos de la formación, tanto de grado como de posgrado, es creciente el número de estudiantes que recurre a diversas metodologías de análisis de los fenómenos discursivos.

Los trabajos aquí reunidos, en los que se toman en cuenta los niveles en los que opera el lenguaje - sintáctico, semántico y pragmático-, se ocupan de una gama de temas que en términos generales ayudan a entender aspectos como los procesos de construcción de identidad nacional, cómo la sociedad ha distinguido lo que es "normal" de lo que no lo es,

\footnotetext{
${ }^{1}$ Coordinada por Teresa Carbó y luego por Eva Salgado Andrade, sesionó en el Centro de Investigaciones y Estudios Superiores en Antropología Social de 1996 a 2010, cuando cambió su sede a El Colegio de México, bajo la coordinación de Danielle Zaslavsky.
} 
cómo la democracia se instaura o no en la esfera pública, los sentidos que subyacen a la argumentación en el debate parlamentario o la forma en que puede estudiarse un discurso en circunstancias de interculturalidad. Esta diversidad temática es analizada por otras tantas propuestas metodológicas, que van desde acercamientos centrados en lo semántico, la reflexión meticulosa sobre las pistas que ofrece la sintaxis, hasta los estudios sobre argumentación o la exploración con base en los actos de habla. Los dos artículos que abren la sección "Saberes y razones" tienen un evidente trasfondo de investigación histórica. Ambos comprueban lo que Michel Foucault aseveró magistralmente:

El documento no es el instrumento afortunado de una historia que fuese en sí misma y con pleno derecho memoria; la historia es cierta manera, para una sociedad, de dar estatuto y elaboración a una masa de documentos de la que no se separa (Foucault, 1982: 10)

Y como advierte Teresa Carbó:

si la sintaxis señala el lugar donde formular las preguntas, es la historia - social, política, económicala que suele poseer las respuestas (Carbó, 1984: 12).

"El significado del silencio entre moradores de La Castañeda en los albores del siglo xx. Consideraciones metodológicas para su tratamiento", de Alicia Llamas Martínez Garza, pone bajo la lupa un conjunto de documentos producidos de manera diferenciada por científicos, médicos de la institución, autoridades judiciales y los propios internos en el contexto de internamiento de locas/delincuentes, confinadas en una de las instituciones orgullosamente inauguradas durante el Porfiriato, y que en 1910 se sumaba a los grandes festejos del Centenario de la Independencia de México. El caso del Manicomio General de la Ciudad de México fue paradigmático en el intento por establecer dispositivos que reforzaran las ideas de orden y progreso, a partir del cual se buscaba silenciar a los indeseables y a los improductivos. Al presentar su marco teórico y metodológico, Llamas asevera que la mayor parte de las disciplinas sociales dependen del dato discursivo proporcionado por los sujetos de la indagación, ya sea en forma oral o escrita. Con fundamento en diversas propuestas teóricas, en las cuales ocupa un lugar prominente la disección que Michel Foucault hace del poder, examina cómo el discurso materializa las relaciones esenciales para comprender la forma en que la locura o la delincuencia son concebidas socialmente. Para la autora el análisis de discurso es una estrategia metodológica capaz de cambiar la manera de concebir tanto "la polifonía como el orden de las correlaciones sujetas a la interacción social de los actores involucrados". El análisis de sus materiales se centra en el silencio, en tanto acto de poder, en la medida en que callar es, paradójicamente, una forma de expresar algo. Visto así, el silencio es una forma de acción. ¿Quién silenció a otros en el caso de los pacientes locos detenidos en calidad de delincuentes?

En "Narrativas deleitosas de la nación. Los primeros libros de cocina en México (1830-1890)", Sarah Bak-Geller Corona emprende el análisis de un tipo de documentos inexorablemente ligado a la vida cotidiana: los recetarios de cocina. Además de ser, en primera instancia, formularios útiles para compartir algo tan preciado para la actividad diaria como los secretos culinarios, adquieren otra dimensión en el siglo XIX en América al consagrarse a la promoción de la idea de una cocina nacional. En las nacientes repúblicas americanas los recetarios alientan la imagen de una cocina:

única, original, con raíces sólidas en el pasado precolonial y por ende diferente a cualquier otra en el continente y en el resto del mundo.

En estas deleitosas recetas, el sentimiento patriótico es el ingrediente principal. A decir de la autora, pese a la importancia de los recetarios en la conformación de los imaginarios a partir de los cuales se gestaba la idea de nación, las ciencias sociales no se han 
ocupado suficientemente de su estudio. Este hecho justifica de sobra uno de los objetivos del artículo: plantear que los elementos narrativos que caracterizan los primeros recetarios americanos expresan imágenes fundadoras de la idea de nación, con lo que se intenta responder a una pregunta central: ¿cómo logró el discurso culinario expresar la idea de nación cuando ésta apenas se constituía en tanto entidad política? Entre las pistas que le permiten ir respondiendo su pregunta, la autora se detiene en las prolijas listas de elogios para los productos naturales de la región. Igualmente, examina otras evidencias en las que no se deja pasar oportunidad para desmitificar el "gusto europeo" y poner en duda su reputación de "delicado". Comparar los atributos de los ingredientes originarios sobre los europeos es una de las fórmulas que comprueban las hipótesis que orientaron esta investigación. Otra estrategia analítica consistió en los notorios esfuerzos por legitimar la ortografía y las locuciones "mexicanas", por ejemplo, al sugerir como ingrediente el xitomate y ros recetarios mexicanos el interés por reconstruir los antecedentes históricos de la nación, en los que la riqueza de los platillos es vista como un testimonio de la grandiosa civilización que habitaba las tierras del Nuevo Continente, mucho antes de la llegada de los españoles.

Se incluyen a continuación dos colaboraciones con una perspectiva más contemporánea, que buscan entender el tránsito de la sociedad mexicana hacia nuevas formas de democracia, así como la manera en que la prensa impresa lo ha reconstruido, o bien los valores que entraron en juego para la histórica despenalización del aborto en la ciudad de México. En el primer texto, "Reconstrucción periodística de nuevas formas de vida democrática (la Marcha del Silencio, abril de 2005)", de Eva Salgado Andrade y Frida Villavicencio Zarza, se emprende una relectura de los encabezados y subencabezados de la primera plana de 15 diarios publicados el día siguiente de la histórica marcha en la que más de un millón de ciudadanos salieron a las calles para

protestar, de manera inusitadamente expresiva, pese al empleo del silencio como elemento principal, frente a lo que se consideró un agravio a la naciente democracia: el intento de desafuero del entonces jefe de Gobierno del Distrito Federal mediante una mal orquestada maniobra para impedir que participara en la contienda electoral por la presidencia en 2006. El análisis de los titulares y los subtitulares se hizo principalmente a partir de las evidencias lingüísticas que contenían: quién figuró como sujeto gramatical, quién fue elidido, cuál fue el sentido de estas elisiones, a qué conocimientos compartidos de los lectores se apelaba en el nivel pragmático de los textos, qué sujeto ocupaba un lugar protagónico, cómo se tematizó la marcha, cómo se reconstruyó el silencio. A casi siete años de distancia de su publicación, el análisis de encabezados y subencabezados confirmó la hipótesis que fue el punto de partida de la exploración: en una abrumadora mayoría, la prensa no estaba preparada para dar relevancia a una auténtica expresión democrática, y optó, en cambio, por destacar el sentido electoral de este episodio, que a la postre se convertiría en uno de los primeros capítulos de la polémica contienda por la presidencia en 2006.

Otro episodio de las nuevas formas de vida democrática es examinado en "Tramas argumentales en el debate legislativo sobre el aborto", de Irma Mariana Gutiérrez Morales, quien relata el proceso que concluyó en abril de 2007, cuando después de cinco meses de debates sobre la despenalización del aborto en la Asamblea Legislativa del Distrito Federal fueron aprobadas reformas al Código Penal local para permitir la interrupción legal del embarazo durante las primeras 12 semanas de gestación. A pesar de que la legislación de la ciudad de México ya admitía cuatro causales para la despenalización del aborto - por imprudencia de la mujer embarazada, por violación, por peligrar la salud de la mujer o por alteraciones congénitas del producto-, lo novedoso y que al mismo tiempo desató la controversia a nivel nacional era que con estas reformas se pretendía flexibilizar al máximo la ley para permitir el aborto a solicitud de la mujer embarazada cualesquiera que 


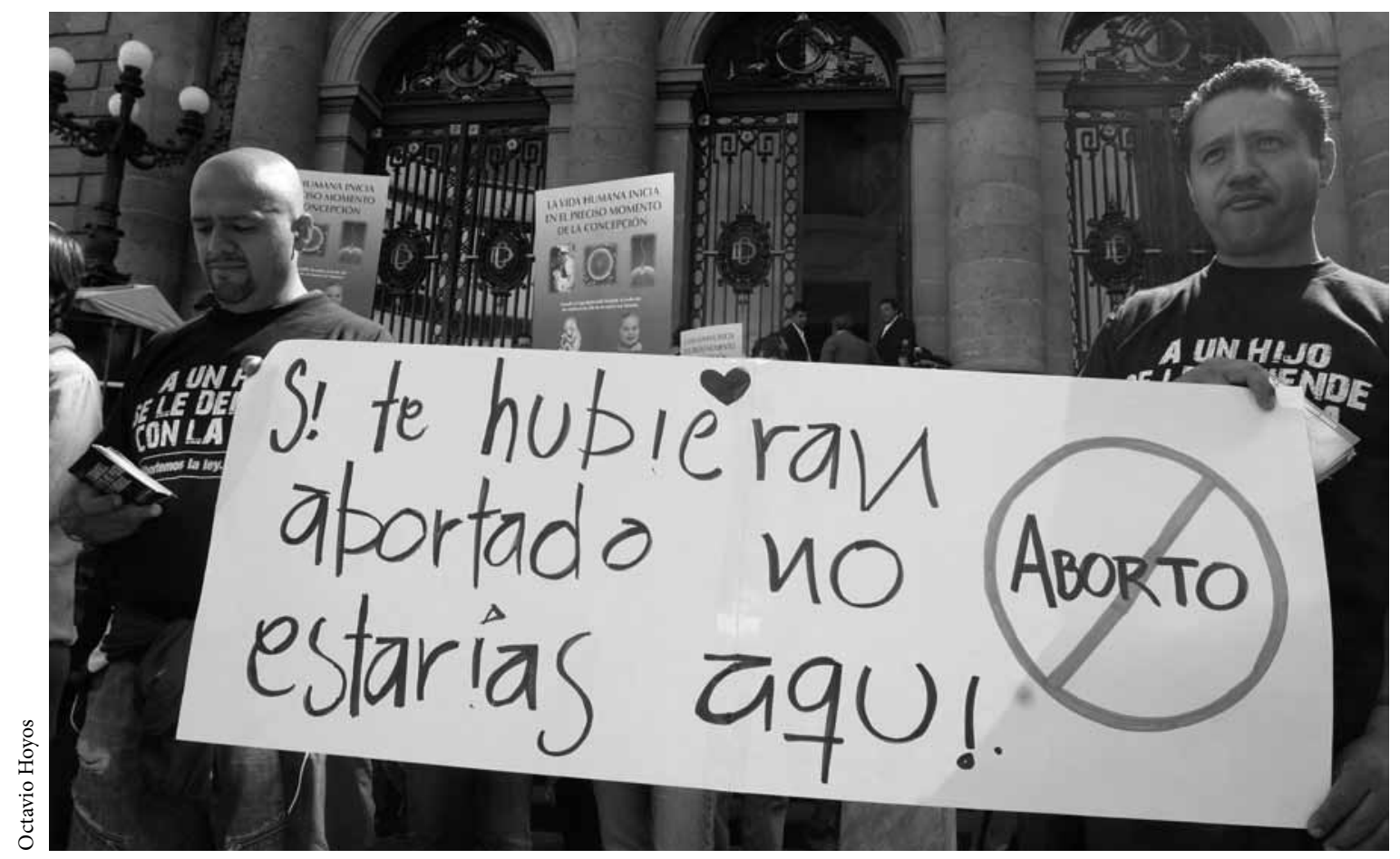

Manifestaciones contra la despenalización del aborto frente a la Asamblea Legislativa del Distrito Federal, 2007.

fueran sus razones. El análisis de Gutiérrez Morales corresponde a los debates que sostuvieron los legisladores del Distrito Federal en el periodo comprendido de noviembre de 2006 - con la presentación de las propuestas de reforma ante el pleno de la Asamblea — hasta abril de 2007 - fecha en que se deliberó y votó el dictamen-. Se pretende mostrar cuáles fueron los objetos discursivos predominantes en la argumentación general, cómo se tejieron tramas argumentales para justificar las posturas de los grupos parlamentarios y cómo se manifestaron alianzas y confrontaciones a partir de la configuración lingüística y argumentativa de los oradores. Como en todo discurso político, los textos que conformaron el corpus, la ideología y las nociones de poder fueron determinantes para la construcción de ciertas representaciones de la realidad. Este trabajo muestra la forma en que los debates parlamentarios se sostienen en argumentos que valen tanto por la fuerza racional de su contenido como por el potencial estratégico de su ubicación en el entramado discursivo.

Evelyn Norma Castro Méndez explora una zona geográfica totalmente distinta en "Conocer y comprender al otro: la comunicación intercultural de Al-Qaeda", artículo en el que se analizan los mensajes emitidos por la red terrorista en el marco de los atentados en Nueva York, Estados Unidos (2001), Madrid, España (2004) y Londres, Inglaterra (2005). Esta investigación representa un encuentro con el otro, ${ }^{2}$ aparentemente distinto y lejano a nosotros, para tratar de aproximarnos al sentido de sus mensajes, esclarecer qué quiso decir Al-Qaeda a Occidente, cuáles son los agravios que le reclaman y cuál era el propósito de los comunicados. El estudio no tuvo por objetivo justificar sus acciones, porque la violencia jamás tendrá sustento, sino entender, pese a

${ }^{2}$ Cabe recordar que el estudio del otro es precisamente uno de los ejes tradicionales de investigación antropológica. 
las diferencias socioculturales, por qué el otro ha recurrido a acciones violentas. Conocer al otro nos permite acercarnos a su entorno, sus creencias, su historia y su lengua, para comprobar que en la comunicación intercultural es posible hacer a un lado los prejuicios y observar que hay puntos de coincidencia, como la injusticia, el despojo, la pobreza, el abuso de poder, que las expresiones radicales de una minoría no representan a la totalidad y que, por el contrario, las denuncias presentadas por Al-Qaeda deberían convertirse en una autocrítica productiva para el sistema occidental. Los mensajes resumen el problema de la región de Medio Oriente y las consecuencias del fracaso de los modelos económicos y políticos impuestos en la zona por las potencias occidentales al defender por un lado la democracia y los derechos humanos y por el otro sostener a gobiernos despóticos y aprovecharse de los recursos geoestratégicos de la región.

Esperamos que este conjunto de textos ejemplifique de manera suficiente el amplio potencial analítico e interpretativo de los estudios centrados en el discurso para la investigación en ciencias sociales, tanto para quienes comparten con nosotros este interés como para quienes pudieran considerar un desacato la irrupción de la lingüística y la semiótica en sus terrenos.

\section{BIBLIOGRAFÍA}

Bolívar, Adriana (comp.), 2007, Análisis del discurso. ¿Por qué y para qué?, Los Libros de El Nacional, Universidad Central de Venezuela (Colección Minerva, Manuales Universitarios), Caracas.

Calsamiglia Blancafort, Helena y Amparo Tusón Valls, 1999, Las cosas del decir. Manual de análisis del discurso, Ariel, Barcelona.
Carbó, Teresa, 1984, Discurso político: lectura y análisis, Centro de Investigaciones y Estudios Superiores en Antropología Social, Secretaría de Educación Pública, México.

Chilton, Paul A. y Christina Schaffner (eds.), 2002, Politics as Talk and Text: Analytic Approaches to Political Discourse, John Benjamins Publishing Co. (Discourse Approaches to Politics, Society, and Culture Series, vol. 4), Filadelfia.

Eco, Umberto, [1977] 1986, La estrategia de la ilusión, Lumen, Barcelona.

Fairclough, Norman, 1995, Critical Discourse Analysis: The Critical Study of Language, Addison-Wesley Publishing Co., Londres.

Foucault, Michel, 1982, La arqueología del saber, Siglo XXI, México.

—, 1988, “El sujeto y el poder", en Hubert L. Dreyfus y Paul Rabinow, Michel Foucault: más allá del estructuralismo y la hermenéutica, Universidad Nacional Autónoma de México, México.

Fowler, Roger et al., 1983, Lenguaje y control, Fondo de Cultura Económica, México.

Gee, James Paul, 2002, An Introduction to Discourse Analysis: Theory and Method, Routledge, Gran Bretaña.

Giménez, Gilberto, 1981, Poder, Estado y discurso. Perspectiva social y semiológica del discurso político-jurídico, Instituto de Investigaciones Jurídicas-Universidad Nacional Autónoma de México, México.

Pardo Abril, Neyla, 2007, Cómo hacer análisis crítico del discurso. Una perspectiva latinoamericana, Frasis, Santiago de Chile.

Renkema, Jan, 1999, Introducción a los estudios sobre el discurso, Gedisa, Barcelona.

van Dijk, Teun A. (comp.), 2000a, El discurso como estructura y como proceso. Estudios sobre el discurso I. Una introducción multidisciplinaria, Gedisa, Barcelona.

- (comp.), 2000b, El discurso como interacción social. Estudios sobre el discurso II. Una introducción multidisciplinaria, Gedisa, Barcelona.

Wodak, Ruth y Michal Meyer, 2003, Métodos de análisis crítico del discurso, Gedisa, Barcelona. 